\title{
INTRAEMPREENDEDORISMO: um estudo de caso sobre o entendimento e a aplicação do termo em uma instituição bancária
}

\author{
1- Nelson Chieh \\ Fundação Getulio Vargas de São Paulo (FGV-EAESP) \\ nelson.chieh@uol.com.br
}

\author{
2- Tales Andreassi \\ Fundação Getulio Vargas de São Paulo (FGV-EAESP) \\ tales1@uol.com.br
}

\section{RESUMO}

O objetivo deste artigo é analisar o entendimento dos funcionários de um grande banco brasileiro sobre o tema intraempreendedorismo, bem como sua aplicabilidade à empresa. Para tanto, foram efetuadas 19 entrevistas com gestores, executivos e funcionários da organização estudada. Como resultado, verificou-se que o termo intraempreendedorismo ainda é pouco conhecido na empresa, muito embora os conceitos e fundamentos ligados ao termo sejam compreendidos. A existência de diversos programas institucionais relacionados ao intraempreen-dedorismo é um forte indício de que a empresa busca valorizar e atrair cada vez mais funcionários com perfil intraempreendedor. Contudo, o entendimento sobre essas iniciativas organizacionais não é homogêneo entre as áreas. Verificou-se também que o incentivo e reconhecimento ao profissional intraempreendedor ainda é muito dependente de ações individuais dos gestores diretos.

\section{Palavras-Chave}

Intraempreendedorismo, intraempreendedor, empreendedorismo corporativo, inovação.

\section{ABSTRACT}

This paper aims at analyzing the understanding of company staff observed concerning matters associated to the theme intrapreneurship, as well as its application within the company. In this study, the existence of corporate practices will also be verified that aim towards the encouragement of intrapreneurship. Using interview techniques, it is intended to verify the level of staff knowledge about the concepts associated to intrapreneurship. The human resource corporate programs and the cultural change will be analyzed through the light of the characteristics of an intrapreneurial organization with the purpose of identifying the existence or not of institutional incentive.

\section{Keywords}

Intrapreneurship, intrapreneur, corporate entrepreneurship, innovation. 


\section{Introdução}

Vários estudiosos de temas ligados à competitividade empresarial vêm apontando a relevância da inovação na formação de vantagens competitivas das empresas. Muitos deles consideram a criação de um ambiente intraempreendedor como fator chave para estimular a inovação e, conseqüentemente, alcançar o sucesso empresarial. Russell (1999), por exemplo, afirma que a prática do intraempreendedorismo tem sido o foco de crescente atenção não só dos executivos como também dos acadêmicos. De forma semelhante, a habilidade de inovar também assumiu uma importância crucial para empresas inseridas em indústrias de rápida evolução.

Certamente, é um grande desafio para as empresas manterem o espírito empreendedor de seus funcionários à medida que elas crescem, estabilizam-se e alcançam certo grau de sucesso. Isso acontece porque algumas condições que propiciam o intraempreendedorismo são neutralizadas no processo de expansão/crescimento em que a organização aumenta o número de funcionários, introduz novas camadas de gerenciamento, novas estruturas, novas políticas e novos procedimentos operacionais, muitos dos quais considerados pelos funcionários como práticas burocráticas.

Hashimoto (2006) comenta que muitos acreditam que a única forma de um funcionário exercitar seu espírito empreendedor é deixar a empresa e criar um negócio por sua iniciativa própria. Os gestores ainda enxergam um potencial conflito de interesse entre a corporação e os funcionários ávidos em desenvolver seu "projeto pessoal" dentro da empresa. Eles entendem que um funcionário não conseguiria dedicar-se à empresa tendo essa idéia e ambição. Essa falsa dicotomia ou aparente conflito de interesses entre empresa e funcionário empreendedor foi desfeito por Pinchot na década de 80. O conceito de intraempreendedorismo criado por ele abriu um caminho alternativo para o melhor aproveitamento dos recursos humanos que as empresas possuem (Pinchot, 1989).

O objetivo deste artigo é analisar o entendimento dos funcionários de um grande banco brasileiro sobre o tema intraempreendedorismo, bem como sua aplicabilidade à empresa. A seguinte pergunta reflete o problema de pesquisa a ser analisado neste trabalho: como o intraempreendedorismo é entendido pelos profissionais da empresa analisada e como ele é aplicado na organização?
É interessante ressaltar que a prática do intraempreendedorismo pressupõe uma certa dose de flexibilidade, o que de certa forma vai de encontro à cultura organizacional comumente encontrada nas instituições bancárias, geralmente caracterizada por polítcas mais estruturadas, com normas e regulamentos rígidos a serem seguidos. Se por um lado há uma exigência crescente para que os gestores de grandes empresas tenham mais criatividade e assumam cada vez mais riscos, por outro lado seus modelos de negócio forçam os mesmos gestores a gastar uma fração cada vez maior do seu tempo lidando com as "amarras corporativas", tais como orçamentos rígidos, elaboração de relatórios de controle, memorandos, justificativas e explicações. Essa contradição acaba fazendo do tema intraempreendedorismo um grande desafio a ser vencido pelas organizações dos dias de hoje.

\section{Referencial Teórico}

\subsection{Conceitos}

Antes de se abordar o tema intraempreendedorismo propriamente dito, vale uma breve discussão sobre inovação. Esta discussão inicial se faz necessária pelo fato de que, em uma quantidade relevante de estudos, inovação e criatividade estão associadas às possíveis motivações que levam à adoção de intraempreendedorismo nas empresas.

De acordo com Russell (1999), a inovação, na concepção Schumpeteriana, pode ser considerada como:

- A implementação de mudanças em produtos ou processos que resultam em melhorias significativas na relação "performance-toprice". Dessa forma, a empresa será capaz de oferecer aos seus clientes produtos ou serviços com um valor agregado maior.

- A geração de novos produtos ou processos que cria um nicho de mercado inédito.

- Abertura de um novo mercado, ou seja, um mercado em que uma área específica da indústria ainda não tenha penetrado, independentemente do fato do mercado existir antes ou não.

- A conquista de uma nova fonte de suprimento de matéria prima ou bens parcialmente manufaturados, independentemente do fato da fonte existir antes ou não. 
- O aparecimento de uma nova estrutura de organização em um setor, como a criação de uma posição de monopólio ou a quebra de um monopólio existente.

A razão dessa distinção é diferenciar as grandes inovações, que representam uma mudança nãolinear, das inovações incrementais, que são melhorias lineares em algo já existente. Os conceitos a serem abordados neste trabalho são mais aplicáveis àquelas organizações que incorporaram o empreendedorismo na sua estratégia empresarial e que busca de forma persistente a inovação como uma fonte de vantagem competitiva, contrastando com aquelas empresas que buscam mudanças inovadoras de forma esporádica.

De certa forma, pode-se vincular o intraempreendedorismo ao processo de inovação. Segundo Antoncic (2001), o intraempreendedorismo pode ser definido pelo seu conteúdo, ou seja, pelas suas dimensões baseadas no conceito de inovação criado por Schumpeter. Dessa maneira, Antoncic (2001) define a atitude intra-empreendedora como a determinação em busca da solução nova ou criativa para desafiar e confrontar as velhas práticas da empresa, incluindo o desenvolvimento e a melhoria de velho ou novo produto, serviço, mercado, técnica de administração e tecnologias para desempenhar as funções organizacionais, assim como mudanças em estratégias, nas suas organizações e na forma com que a empresa lida com os competidores num âmbito mais amplo. Ainda de acordo com ele, o intra-empreendedorismo refere-se a um processo interno de uma empresa existente, independente do seu tamanho, e lida não somente com novos negócios, mas também com outras atividades e orientações inovadoras.

O termo intra-empreendedorismo foi cunhado na década de 1980 pelo consultor de administração Gifford Pinchot III. A seguir, algumas definições sobre intra-empreendedorismo e intraempreendedor.

Para Pinchot (1989), os intrapreneurs são todos os sonhadores que realizam. Aqueles que assumem a responsabilidade pela criação de inovações de qualquer espécie dentro de uma organização. O intrapreneur pode ser o criador ou o inventor, mas é sempre o sonhador que concebe como transformar uma idéia em uma realidade lucrativa.

Já Zahra (1995) aborda duas dimensões em sua definição do intra-empreendedorismo: o foco na inovação e criação de negócios e a renovação estratégica. A primeira dimensão inclui o compromisso da empresa em construir novos produtos ou processos, criando novos mercados ou expandindo os já existentes. A segunda dimensão, renovação estratégica, é a revitalização das operações, mudando o escopo do negócio ou a sua abordagem competitiva.

Para Pryor e Shays (1993), o intraempreendedorismo é a criação de um ambiente no qual a inovação pode florescer de forma a transformar pessoas comuns, que nunca viram um cliente, em empreendedores de sucesso que assumem responsabilidades e papéis dentro da empresa.

De acordo com Andreassi (2005), o termo intraempreendedorismo pode ser entendido, em linhas gerais, como a capacidade que os funcionários de uma empresa têm para agir como empreendedores. Ele menciona também outra definição dada por Dornelas (2003 apud ANDREASSI, 2005):

\footnotetext{
Empreendedorismo corporativo pode ser entendido como o processo pelo qual um indivíduo, ou um grupo de indivíduos, associados a uma organização existente, criam uma organização ou instigam a renovação ou a inovação dentro de uma organização existente.
}

O desenvolvimento do intra-empreendedorismo também surge como uma forma de reter esses talentos dentro das empresas e ao mesmo tempo lidar de forma mais eficaz com as ameaças do mercado concorrente. Na visão de Hashimoto (2006), ao incentivar o intra-empreendedorismo, as empresas estariam aproveitando o melhor dos dois mundos: canalizar o espírito empreendedor dos funcionários para a empresa em troca de estrutura para os empreendedores tocarem os projetos pessoais que estejam alinhados com os objetivos estratégicos da organização.

\subsection{Práticas de Intra-Empreendedorismo nas Organizações}

Eesley e Longenecker (2006) realizaram um estudo que contou com a colaboração de 179 gerentes de mais de 20 empresas de manufatura e de serviços dos EUA e explorou a experiência dos participantes com o intra-empreendedorismo. Os participantes foram instruídos a responderem as seguintes questões:

- Baseado na sua experiência, há alguma ação ou prática/política organizacional que iniba 0 intra-empreendedorismo na sua empresa?

- Baseado na sua experiência, há alguma ação ou prática/política organizacional que 
sua empresa pode adotar para estimular o intra-empreendedorismo?

Durante a pesquisa, todos os participantes mencionaram que suas empresas passam por mudanças organizacionais relevantes provocadas por crescente pressão pelo aumento de competitividade. Setenta e sete por cento dos participantes da pesquisa são homens e vinte e três por cento, mulheres, e todos têm em média 12,3 anos de experiência gerencial. Todos os participantes declararam que possuem subordinados responsáveis pela produção ou serviços a clientes. Os quadros 1 e 2 contêm as respostas a ambas as questões.

Quadro 1 - As principais barreiras às práticas de intra-empreendedorismo

\begin{tabular}{|c|c|}
\hline \multicolumn{2}{|l|}{ As dez principais barreiras ao intra-empreendedorismo } \\
\hline Barreiras apontadas pelos entrevistados & Freqüência \\
\hline Possibilidade de punição pelo insucesso devido ao risco assumido, idéias novas e falhas & $57 \%$ \\
\hline Falta de canal para exposição/execução de novas idéias ou sugestões & $44 \%$ \\
\hline $\begin{array}{llllll}\text { Falta de medidas organizacionais para estimular, promover e encorajar intra- } \\
\text { empreendedorismo }\end{array}$ & $38 \%$ \\
\hline Falta de políticas para coibir disputas internas e falta de cooperação & $35 \%$ \\
\hline $\begin{array}{l}\text { Falta de comunicação interna e existência de redutos que visam à manutenção de status } \\
\text { quo }\end{array}$ & $31 \%$ \\
\hline Pessoas sem visão crítica em busca de novas oportunidades & $28 \%$ \\
\hline Falta de clareza da missão, prioridade e objetivos organizacionais & $26 \%$ \\
\hline Falta de suporte gerencial às novas iniciativas & $23 \%$ \\
\hline Falta de recompensa às ações empreendedoras & $21 \%$ \\
\hline Disponibilidade inadequada de tempo ou de recursos para novos empreendimentos & $18 \%$ \\
\hline
\end{tabular}

Fonte: Eesley e Longenecker (2006)

Quadro 2 - As boas práticas para incentivar o intra-empreendedorismo

\begin{tabular}{||c|c||}
\hline \multicolumn{2}{|c||}{ As dez medidas para incentivar o intra-empreendedorismo } \\
\hline Medidas de incentivo apontadas pelos entrevistados & Freqüência \\
\hline $\begin{array}{c}\text { A cultura de delegação de poder, de assunção de risco } \\
\text { e de ação da força de trabalho }\end{array}$ & $52 \%$ \\
\hline $\begin{array}{l}\text { Celebração e premiação para sugestões, idéias, } \\
\text { progressos e resultados alcançados }\end{array}$ & $41 \%$ \\
\hline Canais de comunicações internos livres e eficientes & $40 \%$ \\
\hline $\begin{array}{l}\text { Suporte gerencial e engajamento de todos os níveis } \\
\text { hierárquicos }\end{array}$ & $36 \%$ \\
\hline $\begin{array}{l}\text { Contínuo engajamento e incentivo à assunção de risco e } \\
\text { novas idéias }\end{array}$ & $35 \%$ \\
\hline $\begin{array}{l}\text { Desenvolvimento de processos para geração e } \\
\text { implementação de novas idéias }\end{array}$ & $33 \%$ \\
\hline $\begin{array}{l}\text { Clara definção das necessidades, visão e direção } \\
\text { organizacional }\end{array}$ & $30 \%$ \\
\hline $\begin{array}{l}\text { Desenvolvimento de cultura de cooperação e de } \\
\text { trabalho em equipe }\end{array}$ & $25 \%$ \\
\hline Disponibilidade de recursos para suportar novas idéias & $19 \%$ \\
\hline $\begin{array}{l}\text { Treinamento interdisciplinar e designação de missões } \\
\text { especiais (fora das atividades cotidianas) }\end{array}$ & $17 \%$ \\
\hline \hline
\end{tabular}

Fonte: Eesley e Longenecker (2006)

São apresentadas, a seguir, algumas conclusões dessa pesquisa. Sobre as barreiras ao intra-empreendedorismo identificadas nesse estudo, há algumas observações importantes a fazer. Em primeiro lugar, as principais barreiras apontadas pelos participantes não estão relacionadas à falta de recursos, ou seja, não apontam para razões de natureza financeira ou de falta de tempo, e sim de natureza estrutural ou cultural. De uma maneira geral, a principal barreira apontada pelos entrevistados é a falta de suporte e de engajamento dados pela empresa. E, ainda pior, eles deixam claro que uma cultura de punição e de aversão ao risco combinada com a falta de 
cooperação e falha na comunicação pode minar qualquer esforço em prol do intraempreendedorismo. Adicionalmente, a inexistência de práticas sistemáticas para encorajar e incentivar ações inovadoras também inviabiliza o intraempreendedorismo.

Em segundo lugar, diferentemente do que acontece no caso do empreendedorismo externo, as possíveis ações para eliminar as principais barreiras ao intra-empreendedorismo quase sempre estão fora do alcance dos gerentes, se estes trabalham de forma isolada. Mesmo para empresas com escassez de recursos, há várias ações que podem ser adotadas para revigorar suas operações através de intra-empreendedorismo além da busca por recurso adicional.

O resultado da pesquisa aponta que provavelmente a chave para a implementação de práticas intra-empreendedoras é a criação de uma cultura organizacional que encoraja, estimula e sustenta as ações intra-empreendedoras. Uma cultura organizacional de intra-empreendedorismo cria um ambiente de trabalho em que os funcionários possam ter confiança e expectativa de que suas iniciativas inovadoras serão encorajadas, suportadas e recompensadas pela empresa.

Diferentemente das decisões sobre a disponibilidade de recursos para um determinado empreendimento, as práticas apontadas pelos entrevistados devem ser desenvolvidas contínua e persistentemente e de forma top-down. O comprometimento com a implantação de intraempreendedorismo pode ser obtido, inicialmente, através da definição de visões e metas organizacionais, pelos altos executivos, que dependem de ações intra-empreendedoras para serem atingidos. Em seguida, é importante obter comprometimento da média gerência em pautar suas ações através de políticas, práticas e o desejo de implementar esta mudança organizacional. Os gestores devem criar mecanismos que identificam, selecionam e suportam iniciativas intraempreendedoras e recompensar o autor dessas iniciativas. Finalmente, numa atmosfera interna de confiança obtido por meio de canais de comunicação eficientes e de espírito de equipe, os gerentes poderão criar oportunidades internas aos funcionários para aplicar seus conhecimentos e exercitar seus espíritos empreendedores.

Goosen, Coning e Smit (2002), apontaram num estudo um modelo conceitual sobre 0 intraempreendedorismo em que a influência das posturas gerenciais sobre uma organização é destacada. Neste estudo, analisaram três aspectos organizacionais que caracterizam o intra- empreendedorismo, considerados pelos pesquisadores como os principais. Dois desses fatores, proatividade e inovação, foram considerados como relativos aos aspectos externos da organização. Esses fatores foram extraídos do já conhecido ENTRESCALE elaborado por Knight (1985). O terceiro fator principal diz respeito às posturas gerenciais e foca nos aspectos internos à organização.

O objetivo principal do estudo de Goosen, Coning e Smit (2002) é a identificação de fatores que conduzem e sustentam o modelo clássico de intra-empreendedorismo. O segundo objetivo é o de investigar o relacionamento entre variáveis contextuais tais como idade e tamanho da empresa e o risco do negócio, e os fatores principais relacionados ao intra-empreendedorismo apontados no parágrafo inicial desta seção. O estudo também analisou relações entre os fatores principais já conhecidos — proatividade dos funcionários, inovação e posturas gerenciais - e o tamanho e a idade da empresa.

Era esperado que a capacidade de inovar pudesse ter uma correlação negativa com a idade da organização, uma vez que ela se torna menos inovadora na medida em que avança aos estágios posteriores da evolução organizacional. O resultado do estudo, no entanto, aponta para falta de correlação significativa entre estas variáveis. E, especialmente, conclui que não há indício de que as organizações mais antigas tenham um comportamento menos intra-empreendedor.

Uma outra constatação: há uma correlação negativa significativa entre a idade da organização e a proatividade. Há também uma correlação negativa, porém não significativa, entre idade e a capacidade de inovar e entre idade e posturas gerenciais. O fato de não haver uma correlação significativa entre a variável idade e as variáveis posturas gerenciais e capacidade de inovar pode sugerir que, embora haja em algumas das organizações antigas pesquisadas a falta de capacidade de inovar e de orientação das posturas gerenciais para ações intra-empreendedoras, a maioria das empresas não apresentou o mesmo comportamento.

\section{Metodologia}

A definição do enfoque de um determinado estudo irá depender do objetivo específico e do resultado esperado para o qual a pesquisa está dirigida. De uma maneira geral, uma pesquisa pode ter um enfoque exploratório, descritivo ou causal. Para Andreassi (1994), o objetivo principal dos 
estudos ou pesquisas exploratórios é de conhecerse ou familiarizar-se com o fenômeno estudado ou buscar obter uma nova compreensão deste. A característica desta modalidade de estudo é a falta ou a inexistência de hipóteses. Por sua vez, os estudos descritivos, por apresentarem precisamente as características da situação ou do caso examinado, têm como característica fundamental a exatidão. Devido ao conhecimento prévio das possíveis causas, a exigência de hipótese aparece muitas vezes como uma condição necessária, embora nem sempre indispensável. Por fim, estudos causais ou experimentais têm como objetivo a investigação das possíveis relações de causa e efeito. Dessa maneira, a existência de hipóteses prévias torna-se essencial para alcançar o sucesso nesse tipo de estudo. Como este estudo visa aumentar o conhecimento acerca do fenômeno, esclarecer e aplicar conceitos e apontar possibilidades práticas de realização de pesquisa em situações reais, ele pode ser caracterizado como um estudo exploratório.

Com relação ao método, Yin (2001) relaciona cinco métodos ou estratégias de pesquisa: experimento, levantamento, análise de arquivos, pesquisa histórica e estudo de caso. $\mathrm{O}$ autor apresenta três condições para a definição da estratégia a ser adotada para a pesquisa: tipo de questão da pesquisa, o controle que o pesquisador possui sobre as variáveis envolvidas e o foco em fenômenos que podem ser históricos ou contemporâneos.

Em estudos de caso, a forma da questão de pesquisa está mais relacionada com questões do tipo "como" e "por que", que é o caso do presente trabalho, que tem como questão de pesquisa "como o intraempreendedorismo é entendido pelos profissionais da empresa analisada e como ele é aplicado na organização". Além disso, os estudos de caso se caracterizam também pela dificuldade de controle sobre eventos comportamentais e pela ênfase em um aspecto contemporâneo, sendo um tema pouco explorado tanto do ponto de vista acadêmico quanto do ponto de vista prático. Tais características encontram-se presentes nesta pesquisa, razão pela qual, pode-se classificá-la como uma pesquisa qualitativa exploratória, utilizando-se o método do estudo de caso.

Para corroborar o ponto de vista de Yin (2001) sobre o método de estudo de caso, segundo Selltiz et alii (1975, p. 69-70), "os cientistas que trabalham em áreas relativamente não-formuladas, onde existe pouca experiência que sirva de guia, acham que o estudo de exemplos selecionados é um método muito produtivo para estimular a compreensão e sugerir hipóteses para pesquisa".

A empresa escolhida para a pesquisa é um dos maiores bancos privados brasileiros, que atua em praticamente todos os segmentos do mercado financeiro: varejo, atacado, seguros e previdência privada e gestão de patrimônios. Conta com aproximadamente 2000 pontos de atendimento no Brasil e diversas unidades de negócios no exterior. A escolha da empresa é justificada por dois motivos:

O primeiro diz respeito ao esforço de mudança cultural e organizacional da empresa com o objetivo de diferenciar-se dos demais bancos concorrentes. Foram implementados diversos programas institucionais nos últimos anos visando incentivar o espírito empreendedor de seus funcionários. Estas mudanças não só elevaram o seu nível de retorno financeiro, como também provocaram alterações relevantes na cultura interna. Os autores acreditam que estas mudanças estejam alinhadas às características de uma organização intraempreendedora.

O segundo motivo diz respeito ao acesso às informações detalhadas para realização de análises. Os assuntos relacionados ao intraempreendedorismo estão intimamente associados à cultura organizacional que pode exigir análise de documentos internos muitas vezes de difícil acesso. O fato de um dos autores ser funcionário da empresa estudada pode, de certa forma, facilitar o acesso às informações necessárias para realização do estudo.

Para Yin (2001), as evidências para um estudo de caso podem vir de seis fontes distintas: documentos, registros em arquivo, entrevista, observação direta, observação participante e artefatos físicos. Analisando os pontos fortes e fracos da cada fonte de evidência e levando em consideração o tema a ser estudado, concluiu-se que as técnicas de análise documental e de entrevista são mais indicadas para o presente trabalho. Ao todo foram realizadas 19 entrevistas.

As primeiras entrevistas foram realizadas com cinco profissionais da área de recursos humanos. Essa escolha se deve ao fato dessa área desempenhar um papel estratégico na elaboração de políticas e programas corporativos, relacionando-se com todas as áreas da empresa. As entrevistas foram realizadas de forma individual e seguindo um roteiro previamente elaborado. Ao longo das entrevistas, esse questionário foi enriquecido com as argumentações dos 
entrevistados e impressões do autor registrado através de gravador de voz.

Uma vez obtidas as informações dos profissionais da área de Recursos Humanos, a etapa seguinte da coleta de dados ficou focada em profissionais de diversas áreas da empresa e nos gestores dos programas institucionais apontados nas entrevistas da fase anterior. Dessa forma, acredita-se que obteve-se uma consistência entre as visões da área formadora de políticas, da área gestora dos programas e das demais áreas da empresa.

As respostas das entrevistas eram transcritas, passando por um processo de pré-análise com o propósito de se agrupar as respostas semelhantes. Tendo o indivíduo como unidade de análise, e dado que o objetivo do presente trabalho é analisar o entendimento dos funcionários da empresa analisada sobre o tema intra-empreendedorismo, bem como sua aplicabilidade na empresa, os gestores de diversas áreas foram agrupados de forma a compor quatro subunidades de análises. Para um melhor detalhamento do entendimento que os entrevistados possuem sobre o tema estudado e para se verificar a homogeneidade desse entendimento dentro da empresa, as subunidades de análise foram definidas por cargo e por área/função dos entrevistados. Na dimensão cargo, os entrevistados foram classificados como executivo ou média gerência. Para facilitar a análise, o cargo de executivo contempla os altos executivos e os executivos, enquanto o cargo de média gerência contempla os gerentes e um analista de recursos humanos. Já na dimensão área/função, os entrevistados foram classificados como de área de negócios e operacionais. Sendo que os entrevistados da área de recursos humanos são classificados como de área operacional. Com isso, os autores pretendem tornar mais rico o trabalho de análise, executando-o tanto de forma mais abrangente (visão empresa) quanto mais peculiar (visões por nível hierárquico e área/função).

\section{Apresentação dos Resultados}

\subsection{A Empresa Analisada}

A estrutura organizacional da empresa, antes de 2004, era segregada por áreas de negócio: atacado, varejo, seguros e previdências, cartão de crédito e, por fim, corporativa. Cada uma das áreas, internamente conhecidas como pilares, tinha sua própria estrutura hierárquica, praticamente independente das demais. Em 2004, houve uma mudança significativa na estrutura organizacional.
Os antigos pilares foram extintos e as áreas de suporte e operacionais foram consolidadas em uma única vice-presidência conhecida internamente como Área Corporativa.

De acordo com os entrevistados, essa reestruturação foi o primeiro passo dado pela empresa em direção às características de uma organização intraempreendedora. Acredita-se que a redução de níveis hierárquicos e a consolidação das áreas de suporte e administrativa não só propiciam uma interação maior entre os departamentos, como também facilitam a comunicação interdepartamental.

A seguir, os programas corporativos, apontados pelos próprios entrevistados, serão analisados em maior detalhe, com a perspectiva de verificar sua aderência aos conceitos e fundamentos ligados ao tema intraempreendedorismo. O título dos programas foi substituído por letras, a fim de se evitar identificação da organização estudada.

O Programa A procura provocar uma diferenciação da organização por meio de mudança de atitude de seus colaboradores, através de ações de melhoria e de mudança cultural.

O Programa B objetiva estimular uma mudança de atitude e comportamento dos funcionários por meio da implementação de uma cultura que valoriza parceria interna, comunicação transparente, meritocracia, ambição por um resultado melhor e ambiente menos burocrático.

O Projeto C visa oferecer agilidade, transparência, rapidez, atenção e resolução de problemas aos clientes. O projeto consiste em um processo de redesenho da estrutura e da forma de organizar a rede de agências, reestruturação de cargos e funções, e redesenho funcional da agência.

O Programa D tem por finalidade estabelecer uma atitude proativa nos funcionários, além de incentivá-los a que busquem novos desafios. Com isso, o que a empresa deseja é a mudança do modelo mental dos funcionários por meio de conhecimento e de valorização das atitudes desejadas.

O Programa E consiste em encontros dos altos executivos da empresa (presidente e vice-presidentes) com grupos de funcionários, com o objetivo de aproximar os executivos e profissionais de diversas frentes de negócio. 
O Programa $\mathrm{F}$ permite que os funcionários façam comentários, esclareçam dúvidas e registrem críticas ou elogios, com a garantia de serem atendidos com mais eficiência e rapidez. As mensagens são enviadas para a área de Endomarketing que, dependendo do assunto, as encaminham para as áreas responsáveis.

O Programa $\mathrm{G}$ visa reconhecer as atitudes positivas dos colaboradores por meio de premiação trimestral. A empresa entende que um programa de estímulo à qualidade não deve objetivar a penalização, mas sim incentivar as ações e atitudes positivas.

O Prêmio X é uma premiação anual que tem o objetivo de valorizar e estimular as ações e realizações alinhadas com a estratégia da empresa. Atualmente, há seis categorias de premiação: inovação, sinergia, qualidade, eficiência, geração de negócios e gestão de pessoas.

O Programa $\mathrm{H}$ e o Programa Six Sigma consistem em uma metodologia de análise e de solução de problemas que tem como principal objetivo reduzir defeitos, retrabalhos, erros e falhas. A ação do Programa $\mathrm{H}$ é de livre escolha dos gestores que são incentivados a discutir com sua equipe os problemas de falta de qualidade e identificar as causas e as possíveis soluções.

\subsection{Análise das Entrevistas Realizadas}

As entrevistas foram realizadas entre novembro de 2006 e janeiro de 2007. Ao todo, foram entrevistados 19 funcionários da empresa, assim distribuídos:

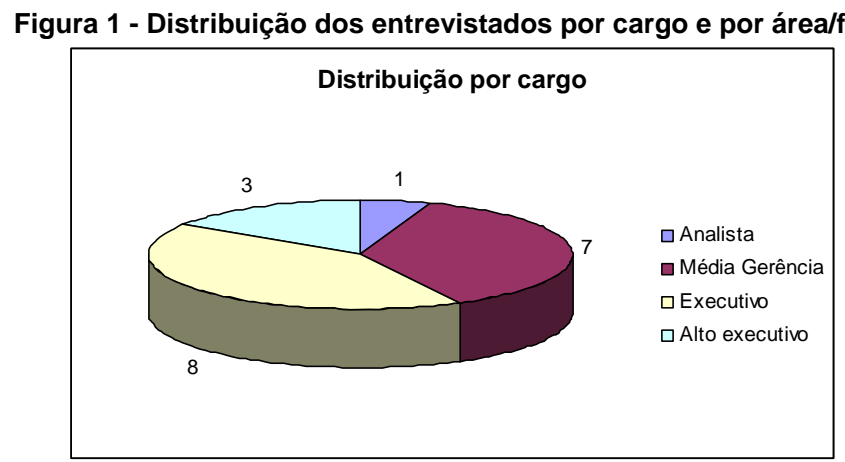

Durante a entrevista, cinco grandes questões formuladas de forma mais abrangente foram apresentadas aos entrevistados. Para cada uma dessas questões, algumas perguntas com finalidades mais específicas também foram feitas.

A primeira questão versou sobre o entendimento do termo intra-empreendedorismo pelos profissionais formadores de políticas e de opiniões, tais como alto executivos e profissionais de recursos humanos. Para uma melhor depuração da análise, quatro perguntas mais direcionadas foram feitas.

Pergunta 1: O termo intraempreendedorismo é familiar a você?

$\mathrm{Na}$ análise por cargo, os entrevistados em cargos executivos conhecem melhor o termo, pois as definições apresentadas estavam próximas do esperado. Já na análise por área ou função, os entrevistados da área de negócios possuem melhor conhecimento do termo intraempreendedorismo. De uma maneira geral, os entrevistados conhecem pouco ou desconhecem totalmente o termo. Quando mencionado pelos entrevistados, o termo intraempreendedorismo ainda está muito associado à inovação.

Pergunta 2: Você concorda com as definições apresentadas?

Foram apresentadas definições formais de intraempreendedorismo e intra-empreendedor aos entrevistados, antes de solicitar sua resposta. Após a exposição formal de algumas definições relacionadas aos dois termos, uma pequena parte dos entrevistados associou, de forma imediata e espontânea, os conceitos apresentados a algum programa institucional, tais como o Programa B ou o Programa G. Outra parte dos entrevistados comentou, da mesma maneira, que a empresa utiliza algum outro termo como, por exemplo, atitude proativa, senso de propriedade e ser protagonista, para designar atitudes de um intraempreendedor. Como houve pouca variação, tanto na perspectiva cargo quanto na perspectiva 
área/função, entende-se que as definições foram bem aceitas pelos entrevistados.

Pergunta 3: De uma maneira geral, você vê a aplicabilidade do intraempreendedorismo na sua empresa?

Não houve discrepância significativa nas duas perspectivas: cargo e área/função. Como a maioria confirmou que sim, pode-se dizer que os entrevistados entendem que os conceitos são aplicáveis na empresa. Alguns entrevistados fizeram a seguinte ressalva: “... é aplicável; porém, não se pode ter uma equipe formada apenas por intraempreendedores..." Isso demonstra um entendimento errôneo desses entrevistados sobre o perfil de intraempreendedor. Acreditam que um intraempreendedor não possui função/perfil de executor, pois, no seu entendimento, um intraempreendedor é responsável apenas pela geração de ideias e não pela sua concretização.

Pergunta 4: É possível identificar os funcionários intraempreendedores na sua empresa?

Não houve discrepância significativa nas duas perspectivas: cargo e área/função. De uma maneira geral, os entrevistados acreditam que é possível identificar os funcionários com perfil intraempreendedor por meio de características pessoais e traços comportamentais.

A segunda questão foi em relação às políticas e mecanismos existentes na organização que estimulam o intraempreendedorismo. Para um melhor entendimento dessa questão, duas perguntas mais direcionadas foram feitas:

Pergunta 1: Você poderia comentar algumas políticas ou práticas organizacionais que visam incentivar o intraempreendedorismo?

Num total de 10 programas analisados, a média de citações dos programas pelos 19 entrevistados foi de 2,7. Esse número é relativamente baixo, o que possivelmente deve ser causado por falta de conhecimento e erro de entendimento. A falta de conhecimento dos entrevistados sobre o tema intraempreendedorismo pode ter prejudicado a identificação dos programas. Outro fator que pode ter provocado a baixa identificação de programas é a associação do intraempreendedorismo apenas à inovação, e não ao processo de melhoria contínua. Por fim, como os entrevistados entenderam que o programa de incentivo está associado apenas à premiação, esse erro de entendimento pode ter dificultado a identificação dos demais programas. Nas entrevistas, percebeu-se que os programas de premiação foram os primeiros citados. Isso reflete um erro conceitual dos entrevistados, que confundem premiação com incentivo. Como mostra a literatura sobre empreendedorismo, dificilmente o desejo de obter uma recompensa ou premiação é o principal motivador dos intraempreendedores. Nessa questão não houve discrepância significativa nas perspectivas cargo e área/função.

Pergunta 2: As necessidades de um possível empreendedor interno podem ser atendidas pelos mecanismos internos e políticas da organização?

De uma maneira geral, os entrevistados acreditam que as necessidades dos intraempreendedores podem ser atendidas pelas políticas e programas existentes. A ressalva é com relação à estruturação desses programas, que nem sempre sinalizam a valorização das atitudes intraempreendedoras pela empresa. Com relação às respostas, não houve discrepância significativa na perspectiva cargo. Na perspectiva área/função, os entrevistados da área operacional tiveram uma opinião mais reticente, pois entendem que há poucas medidas de incentivo ao intraempreendedorismo. Uma provável causa dessa discrepância pode estar relacionada ao escopo de trabalho da área operacional: mais metódico, previsível, planejado e controlado.

A terceira questão colocada aos entrevistados visou saber se as iniciativas organizacionais que estimulam o intraempreendedorismo são compreendidas de forma homogênea nos diversos níveis hierárquicos e se esse entendimento também é homogêneo em diferentes áreas, tais como administrativas e negócios. Para um melhor entendimento da questão, três perguntas mais direcionadas foram feitas.

Pergunta 1: Você concorda com o perfil de intraempreendedor apresentado anteriormente? Qual é o seu grau de concordância?

Não houve discrepância significativa nas duas perspectivas: cargo e área/função. De uma maneira geral, os entrevistados concordam que os perfis apresentados condizem com um possível perfil típico de um intraempreendedor. As perguntas 2 e 3 serão analisadas conjuntamente.

Pergunta 2: Levando em consideração o mercado em que a empresa atua, os fatores circunstanciais e a aplicabilidade na empresa, quais os principais traços de uma organização empreendedora verificados na empresa?

Pergunta 3: Há práticas semelhantes na sua empresa? (Qual é a realidade na empresa?)

Levando em consideração o mercado em que a empresa atua, os fatores circunstanciais e a aplicabilidade na empresa, os entrevistados acreditam que a empresa consegue ter a maioria 
dos traços de uma organização intraempreendedora. A análise segundo a perspectiva cargo revelou que os altos executivos são mais otimistas com relação à possibilidade de se ter as práticas típicas de uma organização intraempreendedora. Da mesma forma, os entrevistados da área de negócios também são mais otimistas com relação aos funcionários das demais áreas. O autor verificou que é quase consenso entre os entrevistados que não é possível para a empresa ter um perfil 100\% intraempreendedor. Quando indagados sobre os motivos ou fatores que impedem a prática plena dos fundamentos de uma organização intraempreendedora na empresa, os entrevistados apresentaram os seguintes argumentos:

- Há uma barreira natural dos funcionários da empresa quanto à inovação;

- Sendo um banco, há necessidade de a empresa preservar a estabilidade das operações, logo ela não pode tolerar iniciativas freqüentes dos intraempreendedores;

- Não se pode desejar ter uma equipe com $100 \%$ de empreendedores; a empresa também precisa de trabalhadores operacionais;

- O tamanho da empresa influencia na aplicabilidade dos fundamentos de uma organização intraempreendedora. Os entrevistados entendem que o banco, com seus mais de trinta mil funcionários $e$ milhares de pontos de venda espalhados, tem pouca chance de sucesso se não tiver um controle mais rígido e um pouco de burocracia.

Acredita-se que esses argumentos apresentam uma série de distorções conceituais. O erro mais comum é associar intraempreendedorismo exclusivamente à inovação, pois poucos entrevistados recordaram que o intraempreendedorismo também pode estar ligado às ações de melhoria contínua. Muitos dos entrevistados ainda têm a percepção de que inovação provoca necessariamente instabilidade e envolve grandes riscos. Há também um erro de entendimento sobre 0 papel dos intraempreendedores, pois os entrevistados os veem apenas como sonhadores e não como executores (implementadores). Por fim, muitos acreditam que o tamanho da empresa é um fator que impede, ou pelo menos limita, a prática do intraempreendedorismo. Notou-se que todos os entrevistados acreditam que há um desejo da empresa de transformar-se em uma empresa mais intraempreendedora.

A quarta questão feita aos entrevistados disse respeito a como uma nova idéia ou iniciativa é tratada dentro da empresa. Para um melhor entendimento, essa questão foi desdobrada em quatro perguntas. As perguntas 1 e 2 serão analisadas conjuntamente.

Pergunta 1: Criatividade e novas idéias são valorizadas pela empresa?

Pergunta 2: Há medidas ou práticas organizacionais que estimulam a criatividade ou inovação?

Em geral, os entrevistados acreditam que a empresa valoriza novas idéias e inovações. Não houve discrepância relevante na perspectiva cargo. $\mathrm{Na}$ perspectiva área/função, pode-se verificar que a área operacional apresentou um grau de concordância menor. Acredita-se que possa haver pelo menos duas explicações para isso. A primeira está relacionada ao fato de que os entrevistados ainda associam novas idéias ou inovação a novos produtos ou serviços. Como a participação da área operacional no processo de criação e concepção de novos produtos e serviços ainda não é muito freqüente, o resultado pode estar refletindo a sua exclusão nesse processo. A segunda diz respeito à noção de que novas idéias e inovações ainda estão associadas à criação de novos produtos e serviços, deixando de fora a melhoria contínua. Como as atividades da área operacional ainda estão muito associadas a essa forma de intra-empreender, acredita-se que os entrevistados dessa área acabaram sendo influenciados por esse viés no entendimento.

Com relação à existência de medidas ou práticas organizacionais que estimulem a inovação, os entrevistados entendem que não há medidas organizacionais com essa finalidade. $\mathrm{Na}$ perspectiva cargo, a concordância com a existência de medidas organizacionais é mais elevada entre os executivos. Isso pode ser o reflexo do viés negativo da inovação do tipo top-down, que é mais valorizado na empresa. $\mathrm{Na}$ perspectiva área/função, o grau de concordância dos entrevistados da área de negócios quanto à existência de medidas que estimulem a inovação foi mais elevada. Isso pode ser conseqüência do escopo de trabalho da área, uma vez que os funcionários dessas áreas lidam com inovação no seu cotidiano.

As perguntas 3 e 4 serão analisadas conjuntamente. 
Pergunta 3: Na sua empresa, há alguma área responsável pela criação ou identificação de novas idéias? Há algum processo ou fluxo pelo qual uma nova idéia pode ser validada ou viabilizada?

Pergunta 4: Como as novas idéias são tratadas na sua área?

Nessas perguntas, não houve discrepância significativa nas perspectivas cargo e área/função.

Quanto à existência de área responsável pela criação, alguns poucos entrevistados citaram as áreas de Produtos, Marketing e Comercial. No entanto, é quase um consenso dos entrevistados que cada um é responsável pelas inovações da sua própria área. Dessa forma, pode-se entender que as inovações são geradas de forma disseminada, não havendo, portanto, uma área específica para tal. Quanto à existência do fluxo formal para validação das novas idéias, quase todos os entrevistados consideraram que, formalmente, o fluxo não existe. Os entrevistados entendem que a validação ainda depende de iniciativas individuais e do apoio do gestor imediato.

A quinta questão teve por finalidade saber se as atitudes intraempreendedoras são levadas em conta na contratação e na promoção de funcionários. Com relação à contratação de novos funcionários, a maioria dos entrevistados respondeu que há uma intenção da organização em buscar funcionários com perfil intraempreendedor. $\mathrm{Na}$ promoção, porém, a entrega de resultado ainda é muito valorizada. Os entrevistados apontaram o fato de que, tendo um nível de entrega compatível com o esperado, os funcionários com perfil intraempreendedor podem eventualmente levar certa vantagem (prioridade) na promoção. Quase todos os entrevistados deixaram claro que tanto no caso de contratação, quanto no caso de promoção, a busca por pessoa com perfil intraempreendedor ainda não é uma realidade institucional. Ou seja, ela ainda depende muito do desejo do gestor imediato e do perfil da área.

\section{Conclusões}

Com relação ao entendimento do termo intraempreendedorismo e os assuntos associados a ele, pode-se dizer que o termo, no sentido literal, ainda é pouco conhecido. Embora os entrevistados conhecessem o significado de empreendedorismo, apenas uma minoria já tinha ouvido falar do termo intraempreendedorismo, embora tivessem uma noção geral do sentido do termo.

Com relação aos mecanismos formais de incentivo ao intraempreendedorismo, percebe-se que há uma clara orientação estratégica da empresa em incentivar as atitudes ligadas ao intraempreendedorismo. A existência de diversos programas institucionais é um forte indício de que os gestores são orientados a valorizar e atrair cada vez mais funcionários com perfil intraempreendedor. Embora a maioria dos programas institucionais atue como ferramenta de orientação e não como uma imposição ou como regras rígidas a serem seguidas pelos gestores, eles são bastante abrangentes quanto aos fundamentos de uma organização intraempreendedora. Além desses programas de orientação, os funcionários também contam com diversos programas de premiação, que de certa forma reforçam os comportamentos e atitudes intraempreendedores.

De uma maneira geral, pode-se dizer que há diversos programas e ferramentas institucionais que visam estimular o intraempreendedorismo de forma direta e explícita. O entendimento sobre essas iniciativas organizacionais, porém, não é homogêneo entre as áreas. Enquanto as áreas de negócios entendem que há medidas organizacionais estruturadas para incentivar o intraempreendedorismo, as outras áreas não compartilham da mesma opinião. Entende-se que talvez o desafio da empresa resida em estruturar um plano de comunicação reforçando o propósito de cada mecanismo, ou seja, comunicando de forma mais clara e direta que o novo objetivo empresarial só poderá ser atingido por meio de ações intraempreendedoras que esses programas pretendem incentivar.

Quanto à aplicabilidade dos conceitos ligados ao intraempreendedorismo, em geral todos concordam que ao incentivar as ações intraempreendedoras e valorizar os intraempreendedores, a empresa terá uma enorme vantagem competitiva frente aos seus principais concorrentes. Nessa questão, os executivos são mais otimistas em relação aos gerentes de nível médio. Isso demonstra que as práticas de incentivo ao intraempreendedorismo, bem como a compreensão sobre o propósito dos programas de incentivo, ainda não são homogêneas. na empresa.

Com relação ao tratamento dado pela empresa às iniciativas criativas, os entrevistados acreditam que elas são valorizadas pela empresa, embora não haja um mecanismo formal de incentivo à criatividade. O mesmo entendimento também é válido quanto à inexistência de uma área centralizada responsável pela inovação. Se, por um lado, essa realidade se aproxima do fundamento de uma empresa intraempreendedora, por outro lado, 
a falta de um acompanhamento centralizado sobre as inovações de maior impacto pode ser prejudicial.

Há uma discrepância com relação ao processo de criação dentro de cada área em comparação ao processo institucional, pois os entrevistados acreditam que, mesmo informalmente, eles procuram proporcionar maior espaço aos membros da equipe para sugestões e idéias. Esse fato reforça ainda mais o comentário do parágrafo anterior sobre a centralização no acompanhamento dessas iniciativas para que, projetando essa realidade de forma institucional, todos tenham a mesma percepção.

Finalmente, quanto ao valor dado às atitudes empreendedoras na seleção e na promoção dos funcionários, todos concordam que a empresa busca valorizar funcionários com esse perfil por meio da orientação estratégica demonstrada nos programas institucionais. No entanto, uma avaliação formal do perfil ainda não é uma realidade homogênea, uma vez que a grande maioria dos entrevistados apontou para o fato de que essa valorização ainda depende de ações individuais dos gestores diretos.

É certo que este trabalho não pretendeu esgotar o assunto, uma vez que o intraempreendedorismo ainda é um tema relativamente recente e pouco conhecido, pelo menos do público brasileiro. Como recomendações para estudos futuros, pode-se conduzir estudos mais quantitativos, procurando relacionar a questão do intraempreendedorismo com desempenho organizacional. Outra possibilidade é estudar analisar o tema sob o ponto de vista das chefias, relacionando ambientes intraempreendores com estilos de gerenciamento das chefias.

Acredita-se que o tema mereça atenção das empresas, pois, se bem implementado, pode contribuir para o aumento da competitividade das empresas, a elevação da taxa de retenção de talentos e a melhoria no índice de satisfação dos funcionários.

\section{Referências}

ANDREASSI, T. Avaliação de desempenho de profissionais técnicos : um estudo de casos. 1994. Dissertação (Mestrado em Administração de Empresas) - Faculdade de Economia e Administração da Universidade de São Paulo, São Paulo, 1994.

ANDREASSI, T. Empreendedorismo corporativo. GV Executivo, São Paulo, v. 4, n. 3, p. 63-67, ago./out. 2005.
ANTONCIC, B. Organizational processes in intrapreneurship: a conceptual integration. Journal of Enterprising Culture, s/l, v. 9, n. 2, p. 221-235, jun. 2001.

\section{DORNELAS, J. C. A. Empreendedorismo} corporativo:como ser empreendedor, inovar e se diferenciar na sua empresa. Rio de Janeiro: Campus, 2003.

EESLEY, D.T.; LONGENECKER, C.O. Gateways to intrapreneurship. Industrial Management, v. 48, n. 1, p.18-25, 2006.

GOOSEN C. J.; CONING, T. J.; SMIT, E.M. The development of a factor based instrument to measure corporate entrepreneurship: a South African perspective. South Africa Business Management, p. 39-51, jun. 2002.

HASHIMOTO, M. Espírito empreendedor nas organizações: aumentando a competitividade através do intraempreendedorismo. São Paulo: Saraiva, 2006.

KNIGHT, R. M. Corporate innovation and entrepreneurship in Canada. Business Horizons, 83, 1985.

PINCHOT, G. Intrapreneuring: por que você não precisa deixar a empresa para tornar-se um empreendedor. São Paulo: Harbra, 1989.

PRYOR, A. K.; SHAYS, E. M. Growing the business with intrapreneurs. Business Quarterly, p. 43-45, Spring 1993.

RUSSELL, R. D. Developing a process model of intrapreneurial systems: a cognitive mapping approach. Entrepreneurship theory and practice, p. 65-84, Spring, 1999.

SELLTIZ, C.; JAHODA, M.; DEUTSCH, M; COOK, $\mathrm{S}$. Métodos de pesquisa nas relações sociais. Editora da Universidade de São Paulo, 5. ed., São Paulo, 1975.

YIN, R. Estudo de caso: planejamento e métodos. Porto Alegre: Bookman, 2001.

ZAHRA, S.; COVIN, J. Contextual influences on the corporate entrepreneurship performance relationship: a longitudinal analysis. Journal of Business Venturing, v. 10, p. 43-58, 1995. 